\title{
A LITERATURA PORTÁTIL DE ENRIQUE VILA-MATAS: DA INTERTEXTUALIDADE À ARTE CONCEITUAL
}

\author{
ENRIQUE VILA MATA'S PORTABLE LITERATURE: FROM \\ INTERTEXTUALITY TO CONCEPTUAL ART
}

\author{
Ana Gabriela Dickstein Roiffe ${ }^{1}$
}

\begin{abstract}
RESUMO: Há mais de 40 anos, o escritor catalão Enrique Vila-Matas tem sido um atuante defensor de uma literatura impura. Mais além de uma provocação ao próprio modo de escrever, suas obras dialogam com o espírito mais amplo das artes, especialmente no caso das vanguardas das décadas de 1920 e 1930, dos movimentos integrados de arte dos anos 1960 e 1970 e de certas expressões artísticas na contemporaneidade. A partir de obras como $A$ historia abreviada de la literatura portátil (1985), a página virtual "Versión disidente de Historia Abreviada de la Literatura Portátil", o conto "Porque ela não pediu isso" (2013) e o livro Não há lugar para a lógica em Kassel (2015), o artigo analisa de que modo o termo portátil, usado como categoria, recupera características de um escritor que ultrapassa os jogos intertextuais para se metamorfosear como um autor conceitual.
\end{abstract}

PALAVRAS-CHAVE: Vila-Matas; literatura expandida; arte conceitual; portátil.

ABSTRACT: Catalan writer Enrique Vila-Matas has been an active advocate for impure literature for over 40 years. In addition to questioning his own writing, Vila-Mata's works approach a broader spirit of the arts, especially the 1920s and 1930s' avant-gardes, the 1960s and 1970s' integrated art movements and contemporary expressions. The article analyzes works such as A Brief History of Portable Literature (1985), "A Brief History of Portable Literature (Disidentified Version)", the tale "Porque ela não pediu isso" (Because She Didn't Ask for It), and The Illogic of Kassel (2015), through the concept of portable, which includes not only Vila-Mata's intertexual games, but also his own metamorphosis as a conceptual author.

KEYWORDS: Vila-Matas; expanded literature; Conceptual Art; portable.

Publicado pela primeira vez em 1985, o livro Historia abreviada da literatura portátil tornou-se um dos grandes clássicos do escritor catalão Enrique Vila-Matas, colhendo até hoje críticas que destacam a sua originalidade e consistência. ${ }^{2}$ Essa curta novela de tons ensaísticos apresenta, mais do que uma clara narrativa, a reconstrução de uma atmosfera vanguardista na Europa dos anos 1920, da qual participam personagens, lendas e acontecimentos históricos e

\footnotetext{
${ }^{1}$ Doutora em Letras pelo Programa de Pós-Graduação em Literatura, Cultura e Contemporaneidade da PUC-Rio .

${ }^{2}$ Ver, por exemplo, a resenha do professor Paulo Roberto Pires (2011), para quem o livro "concentra toda a originalidade de Enrique Vila-Matas".
} 
fictícios sem qualquer teleologia. Trata-se de pílulas fragmentárias de um mundo ficcional, costuradas apenas pela existência de uma sociedade secreta, formada por integrantes tão ilustres quanto Walter Benjamin, Marcel Duchamp, Francis Picabia, Georgia O'Keeffe, George Antheil, Paul Morand, Jacques Rigaut, entre uma série de outros pintores, escritores, artistas, fotógrafos e filósofos, que vão se somando à trama ao longo das páginas. Todos esses personagens colaboram para construir um mundo particular, com regras próprias, a começar princípios indispensáveis para integrar a confraria: apresentar um alto grau de loucura, funcionar como uma máquina solteira e cultivar uma obra que coubesse em uma maleta. A eles seguiam-se também os não indispensáveis, mas recomendados, quais sejam: o espírito inovador, a sexualidade extrema, a ausência de grandes propósitos, um nomadismo infatigável, uma tensa convivência com a figura do duplo, a simpatia pela negritude, a arte de cultivar a insolência e a rejeição à ideia de suicídio (VILA-MATAS, 1985, p. 13). De 1924 a 1927, seus integrantes pouco faziam além de trasladar por diferentes cidades europeias, conspirar (divagando sobre temas variados) e participar de festas espetaculares: "Eram como peregrinos medievais para quem o principal era a viagem e pouco importava que fossem a Canterbury, Jerusalém ou Compostela. Apenas buscavam viajar contando histórias uns aos outros" (idem, p. 55). No entanto, como é comum aos grupos secretos, a publicidade sobre sua existência foi a responsável pela diluição do grupo, já que tudo se implodiu após a revelação das histórias por um de seus integrantes, o satanista Aleister Crowley.

Dentre as dimensões que se destacam no livro de Vila-Matas encontra-se, em primeiro lugar, uma intertextualidade exposta, em que as referências são, ao mesmo tempo, reverência nostálgica às vanguardas modernas e exercício intelectual de urdidura, demandando do leitor um estado de desperta atenção. Existe também um cruzamento entre referências históricas e o universo ficcional, salientando múltiplas camadas a serem exploradas e provocando uma constante desconfiança com relação à narrativa. Por fim e relacionado a este último item, um autor-narrador que parece usar a escrita como performance. Por que teria Vila-Matas classificado essa intensa experiência de curta duração como "literatura portátil"? Seria o "portátil" uma espécie de categoria relacionada também à própria atividade ampliada do escritor catalão?

\footnotetext{
${ }^{3}$ No original, "Eran como peregrinos medievales para los que lo principal era el viaje y poco importaba que llegaran a Canterbury, Jerusalém o Compostela. Sólo buscaban viajar contandóse historias.”. Tradução minha.
} 


\section{Benjamin, Duchamp e Kant: o trio portátil}

Em Historia abreviada da literatura portátil, mais do que a categorização de um conceito "literatura portátil", existe uma espécie de caracterização dos integrantes, nomeados como "os portáteis". A escolha do termo não é apenas denotativa ou etimológica, mas se deve sobretudo às características das obras de dois personagens narrados com relevo no livro: Marcel Duchamp e Walter Benjamin.

O primeiro deles surge num momento anterior à escrita do livro, como disparador indireto da própria ideia do livro. Tudo se inicia com a visita de Vila-Matas à exposição Máquinas celibatárias, exibida no Museu de Artes Decorativas de Paris, em 1976, e logo depois, em 1977, no Centro Georges Pompidou. Tratava-se de uma mostra derivada do livro homônimo de Michel Carrouges (escrito em 1954 e reeditado em 1976), que, por sua vez, inspirou-se na célebre obra de Marcel Duchamp La Mariée mise à nu par ses célibataires, même (1915-23), conhecida como Le Grand Verre, a partir da qual o artista francês decretou a sua rebeldia contra a pintura, deflagrando uma revolução estética e teórica no mundo das artes. No livro, Carrouges compilara obras literárias com diferentes características, reunidas pelo fato de apresentarem máquinas fantásticas, ${ }^{4}$ incluindo entre elas a definição de Gilles Deleuze e Félix Guattari em $O$ Anti-Édipo (1972), que acabava de dar novo fôlego ao termo:

Empreguemos o nome de "máquina celibatária" para designar essa máquina que sucede à máquina paranoica e à máquina miraculante, formando uma nova aliança entre as máquinas desejantes e o corpo sem órgãos, em prol do nascimento de uma humanidade nova ou de um organismo glorioso. (DELEUZE, GUATTARI, 2010, p. 32)

Em meio às máquinas celibatárias, estavam trabalhos de Raymond Roussel, Júlio Verne, Edgar Allan Poe, entre outros, que produziram em suas obras objetos estranhos, de difícil apreensão, gerando imagens fantásticas com traços de morte ou erotismo. Historia abreviada da literatura portátil surge, assim de uma exposição, derivada em um livro, inspirado em uma obra duchampiana, constituindo um tipo de relação que Linda Hutecheon (2011, p. 27) classificaria como "palimpsestuosa".

\footnotetext{
${ }^{4} \mathrm{Ver}<$ http://www.michelcarrouges.fr/bibliographie/romans/les-machines-celibataires/>. Acesso em 17 set. 2019.

${ }^{5}$ No livro Uma teoria da adaptação (2011), a autora retoma o termo de Michael Alexander para justificar a relação de interdependência transgressiva entre as obras, destituindo a ideia de que adaptações seriam secundárias com relação a fontes supostamente originais. Trata-se de uma clara alusão ao livro Palimpsestos: a literatura de segunda mão, de Gérard Genette, publicado pela primeira vez em 1982.
} 
Duchamp retorna no universo ficcional do livro de Vila-Matas, ao lado de Benjamin, formando uma espécie de dupla fundacional (duas almas gêmeas, segundo o escritor), descrita a partir de uma lente que encontra paralelos em trechos de suas vidas e obras:

Ambos foram vagabundos, sempre de passagem, e exilados do mundo da arte, ao mesmo tempo em que colecionistas carregados de coisas, quer dizer, de paixões. Ambos sabiam que miniaturizar é fazer portátil, e que essa é a forma ideal para um vagabundo ou um exilado possuir coisas.' (VILA-MATAS, 1985, p. 11)

Existe, nessa citação, a valorização de um estado desprendido de ambos os personagens, que mantiveram posições de distanciamento e rebeldia, seja em relação às convenções das artes, seja em relação às instituições acadêmicas. Mas sinalizam-se também procedimentos de um "fazer portátil”, que se associa diretamente à maneira como produziram as suas obras e provocaram a linguagem.

No livro, um trabalho de Duchamp torna-se emblema do grupo dos portáteis: as boîtes-en-valise. Iniciadas em 1935, as malas-obras surgiram a partir do desejo do artista de reproduzir pinturas e objetos de que gostava e colecioná-los no menor espaço possível. Se em princípio pensou no livro como suporte, o projeto acabou encontrando sua forma final como um pequeno e portátil museu. Ao arranjar em malas as obras mais importantes que havia realizado em forma de miniatura - a partir de reproduções dos quadros e réplicas de três ready-mades (Fountain, 50 cc air de Paris, and ... pliant, ... de Voyage) -, revisitou a própria obra, reduzindo e dando mobilidade a si mesmo, na medida em que os objetos tornaram-se uma extensão do próprio artista (CAMPBELL, LÉVÈQUE, JUE, 2012, S54). Vila-Matas mostra-se reverente a esse trabalho de Duchamp, determinando a todos os seus personagens que, à semelhança do artista, deveriam carregar consigo suas próprias obras. ${ }^{7}$

De Benjamin, Vila-Matas extrai o seu fascínio por coisas pequenas, como "brinquedos velhos, selos de correio, fotos de cartão postal e paisagens invernais que imitam a realidade, sob a forma de um globo de vidro, que neva quando é sacudido"8 (VILA-MATAS, 1985, p.

\footnotetext{
${ }^{6}$ No original, "Ambos fueron a la vez vagabundos, siempre de caminho, y exiliados del mundo del arte al tempo que colecionistas cargados de cosas, es decir, de pasiones. Ambos sabían que miniaturizar es hacer portátil, y que esta es la forma ideal de poseer cosas para um vagabundo o um exiliado.". Tradução minha.

${ }^{7}$ Lançada em 1941, a série A - uma edição de luxo - foi a única intitulada La boîte-en-valise [a caixa em mala] e que vinha dentro de malas de couro. Continha 68 fac-símiles das suas obras e um trabalho original. Até 1968, foram lançadas outras séries, num total de sete, cuja realização contou com a colaboração de artistas e artesãos convidados pelo próprio Duchamp (CAMPBELL, LÉVÈQUE, JUE, 2012, S52).

${ }^{8}$ No original, "Le gustaban a Walter Benjamin los viejos juguetes, los sellos de correo, las fotos de tarjeta postal y esas imitaciones de la realidad de los paisajes invernales contenidos dentro de un globo de vidrio donde nieva cuando se los sacude". Tradução minha.
} 
11). A escrita de Benjamin efetivamente apresenta o seu gosto pela forma reduzida. Em Passagens, por exemplo, destaca o trecho de um guia ilustrado de 1852, que se tornou uma célebre citação, associando Paris e as passagens do início do século XIX a "um mundo em miniatura":

Essas passagens, uma invenção recente do luxo industrial, têm tetos de vidro, corredores com painéis de mármore, que se estendem através de blocos inteiros de prédios, cujos proprietários se juntaram para erguê-los. Ao largo dos dois lados desses corredores, em que a iluminação vem de cima, estão as mais elegantes lojas. Então, a passagem é uma cidade, um mundo em miniatura. ${ }^{9}$ (BENJAMIN, 2002, p. 15)

O historiador de arte T.J Demos (2002) também encontra um paralelismo em certas condições das trajetórias de Benjamin e Duchamp, que se reflete em suas obras, no que classifica como "estética da mala" (DEMOS, 2002, p. 9). De um lado, a ruptura estética das Boîtes-en-valise de Duchamp, também acompanhada de uma herança afetiva e familiar; do outro, um Benjamin tentando atravessar os Pirineus para fugir do nazismo, carregando "uma mala executiva de couro, um relógio, um cachimbo, seis fotografias, um raio X, óculos, diversas cartas, revistas alguns poucos papeis de teor desconhecido e um pouco de dinheiro" (DEMOS, 2002, p. 8). Embora em condições diferentes, ambos escaparam de Paris no mesmo maio de 1940 e trouxeram, a partir de suas bagagens, relações com o exílio, a falta de moradia, a desterritorialização e a transitoriedade. Demos (idem, p. 19) destaca ainda o quanto as reproduções - seja como conceito ou procedimento - em ambas as obras também funcionariam como representações sem território. Dessas referências, depreende-se que um fazer portátil estaria relacionado a sempre carregar a si mesmo consigo, fazendo um mundo em miniatura, o que em termos metafóricos poderia significar uma forma de se manter um artista íntegro com a sua própria linguagem, mas sempre trasladando para diferentes territórios, como procede mais adiante o próprio escritor catalão. É como se, amparado pela estética da mala, o fazer portátil representasse um constante estado de deriva.

É nesse sentido que o "ser portátil", ou seja, tornar-se parte do seu grupo ficcional de personagens, é ser selecionado por seu espírito inventivo e vanguardista, é demonstrar um caráter tão provocador que comporta a ideia da própria diluição. Essa característica mostra-se

\footnotetext{
${ }^{9}$ No original, "These arcades, a recent invention of industrial luxury, are glass-roofed, marble- paneled corridors extending through whole blocks of buildings, whose owners have joined together for such enterprises. Lining both sides of the arcade, which gets its light from above, are the most elegant shops, so that the passage is a city, a world in miniature.". Tradução minha.
} 
especialmente evidente quando Vila-Matas descreve que a revelação das histórias do grupo, motivo de sua desaparição, demonstrava um desejo da sociedade secreta de surgir e sumir "com a arrogante velocidade do relâmpago da insolência" (idem, p. 14). ${ }^{10}$ Com isso, a exposição do segredo acabou por potencializar a energia dispersiva do grupo, estimulando a concretização do seu verdadeiro leitmotiv:

(...) não por acaso a experiência da literatura é tanto a própria prova da dispersão como a aproximação ao que escapa à unidade, e não deve, portanto, causar estranhamento que a dispersão na qual entrou a sociedade secreta, e com ela a literatura portátil, assinalara também o momento em que ela aproximou-se de si mesma e começou a ser realmente portátil. ${ }^{11}$ (idem, p. 115-116)

É neste trecho, em uma reflexão sobre a própria literatura, que Vila-Matas encontra o que foge à unidade como potência criativa. Nesse sentido, o termo aqui não serviria apenas para denominar aleatoriamente um grupo de artistas em uma peregrinação dândi, mas também um encontro com o âmago do fazer literário, em uma busca que aponta para "o jogo, a troca de identidades, a alegria de ser outro...” (VILA-MATAS, 2015, p. 93). O termo portátil extrapola, dessa forma, o universo do livro, apresentando-se como categoria que acompanha o próprio exercício literário de Vila-Matas: "ser portátil” como desejo de se alocar ao lado de suas referências intelectuais; "fazer portátill" como atividade de reunir o que é mais importante numa obra transportável e deixar-se "vagabundear". O objeto-livro, ao lado da própria escrita, tornam-se portáteis viajantes para novas temporalidades e formas de criar, explorando diferentes territórios artísticos.

Enquanto Duchamp e Benjamin são alocados como os dois grandes exemplos do pensamento portátil, Franz Kafka surge silenciosamente representando o lado obscuro do festivo grupo. No capítulo "Labirinto de odradeks", os três personagens se encontram na narrativa, traduzindo a compósita intertextualidade do livro de Vila-Matas.

Nesse momento, o narrador - um personagem que atua ora como observador, ora como testemunha, ora como coadjuvante dessa saga de grandes - encontra-se com Marcel Duchamp em um café de Port Bou (Espanha), em um fim de tarde de 1966. Além de

\footnotetext{
${ }^{10}$ No original, “(...) la arrogante velocidad del relámpago de la insolencia”. Tradução minha.

${ }^{11}$ No original, “(...) no en vano la experiência de la literatura es tanto la prueba misma de la dispersión como el acercamiento a lo que escapa a la unidad, y no debe, por tanto, extrañarnos que la dispersión en que entró la sociedade secreta, y con ella la literatura portátil, señalara también el momento em que ella se acercó a sí misma y comenzó a ser, por fin, realmente portátil.”. Tradução minha.

${ }^{12}$ A referida citação é um trecho do livro Não há lugar para a lógica em Kassel (2015), que será analisado adiante. Embora retrate um momento posterior de sua obra, foi aqui incluída porque resume aquilo que Vila-Matas, segundo as próprias palavras, mais defendia em sua literatura - ao menos, até então.
} 
conversarem sobre o suicídio de Benjamin naquela cidade 27 anos antes, vivem uma inusitada situação, quando o narrador abre uma garrafa de champanhe e vê a rolha batendo no teto, caindo no topo de um móvel e finalmente equilibrando-se sobre a extremidade da vareta de uma cortina. É nesse momento que surge, no calor da conversa, a figura do odradek, um personagem até então desconhecido, cujas histórias são relatadas por Duchamp para o misterioso narrador. Segundo o artista, os odradeks seriam inquilinos negros secretos, que habitariam o interior de cada um dos portáteis. É aqui que Vila-Matas permite-se confabular com uma das mais instigantes criaturas do universo kafkiano, protagonista do conto "A tribulação de um pai de família". Trata-se de um ser sem origem definida, caracterizado por uma descrição que mais amplia a sugestão do que contorna o traço:

\begin{abstract}
À primeira vista, parece um carretel de linha, achatado e estreliforme; e aparenta, de fato, estar enrolado em fio; é bem verdade que os fios não serão mais do que fiapos, restos emendados ou simplesmente embaraçados de fio gasto, da mais diversa cor e espécie. Mas não se trata apenas de um carretel, pois no centro da estrela nasce uma vareta transversal, de cuja extremidade sai mais outra, em ângulo reto. Com auxilio desta segunda vareta, por um lado, e duma das pontas da estrela por outro, o todo se põe de pé, como sobre duas pernas. (KAFKA, 2008, p. 22)
\end{abstract}

Sem finalidade e na sua totalidade particular, essa criatura "extraordinariamente móvel", de "residência indeterminada", existe apenas para despertar perguntas sobre a mortalidade. "É possível que ele morra?", pergunta-se o pai-narrador. Seria, então, esse ser um corpo avesso à produtividade do capitalismo, como analisou Roberto Schwarz (2008, p. 25), ou apenas um outsider ainda mais inapreensível, posto que atemporal, anárquico e amante de qualquer forma de liberdade? ${ }^{13}$

Em Vila-Matas, no entanto, o odradek muda de personalidade, servindo como um constructo da sua prosa, sob a forma de criaturas ou objetos sombrios, inoportunos e patéticos, que começaram a se deixar ver em Praga e se satisfaziam assustando seus hóspedes ou vítimas (VILA-MATAS, 1985, p. 63). Se em Kafka (2008, p. 23) o inapreensível ser apresenta-se com simpatia ("Evidentemente não faz mal a ninguém”), aqui provoca medo e tensão, levando os portáteis a tomar atitudes inusitadas ou desesperadas. Isso porque os próprios seres alocam-se no seio do jogo textual, construindo-se não apenas como os duplos sombrios dos portáteis, mas elegendo a sua denominação a partir da leitura do conto do escritor tcheco, logo

\footnotetext{
${ }^{13}$ Uma interessante análise do personagem encontra-se no artigo "Odradek, quimera incapturável” (2016), em que o autor, Tomaz Amorim Izabel, procura apresentar a força crítica desse ser que não encaixa nas categorias modernas, a partir do conceito de quimera.
} 
depois de alguns trechos do original serem reproduzidos na história de Vila-Matas (idem, p. 59).

Como terceiro vértice desse trio portátil, Kafka surge, assim, para aportar silêncio, sombra e violência, mas também algumas características do ser portátil. Existe, em primeiro lugar, uma mobilidade que se torna "extraordinária". Mais ainda, revela-se uma elástica capacidade de metamorfose - ilustrada especialmente pela recuperação do termo odradeks para um uso diverso daquele descrito por Kafka. É como se odradek (assim como portátil) fosse uma categoria genérica para expressar diferentes seres cujas formas são flutuantes. ${ }^{14}$

É com essa capacidade fora do comum de se trasladar e um procedimento rigoroso de se manter consistente que Vila-Matas segue o seu trajeto como um escritor portátil.

\section{Versão dissidente: hipertexto ou paratexto?}

Uma nova camada de leitura da História abreviada da literatura portátil encontra-se disponível no site pessoal de Vila-Matas (www.enriquevilamatas.com). Nesse novo ambiente, o escritor portátil assume o caráter migrante da própria obra e uma nova tradução de si mesmo, sob uma abordagem menos aurática. Trata-se, afinal, de uma ousadia descanonizar uma obra consagrada promovendo uma nova experiência, a partir de sua transposição para o meio eletrônico.

Para se chegar à "versão dissidente", percorre-se uma trajetória não intuitiva, como se a chegada fosse fruto de uma casualidade. A página inicial do site oferece três principais entradas. Na primeira delas, chamada de "enrique vila-matas", são introduzidos, por exemplo, dados biográficos, colunas do escritor no jornal El País e um link para o blog Ayudante de Vilnius, onde Vila-Matas publica frases, epígrafes, artigos e resenhas sobre o seu trabalho. $\mathrm{Na}$ segunda, intitulada "perder países", são dispostas referências sobre traduções de seus livros e matérias em jornais de países como França, Portugal e Brasil. Finalmente na terceira, "literatura", uma série de diferentes tipos de informação se misturam, a exemplo de prólogos e livros sobre a sua obra. Dentro desta última entrada, encontra-se o genérico título "texto", que inclui uma imensa listagem de colunas de jornal e entrevistas de Vila-Matas a diferentes

\footnotetext{
${ }^{14}$ É interessante notar que, no livro, Vila-Matas adota, como substituto de portátil, o termo shandy. Trata-se, segundo o autor, de uma nomenclatura derivada de duas fontes: um dialeto onde vivera Lawrence Sterne, autor de Tristam Shandy, que significaria "indistintamente alegre, volúvel e louco" [no original, "indistintamente alegre, voluble y chiflado" (VILA-MATAS, 1985, p. 10)], mas também de uma bebida alcoólica de Londres, que consistia de uma cerveja amarga combinada com limonada ou cerveja de gengibre. Nesse sentido, tão inapreensível seria o portátil que a sua metamorfose estende-se a um nome que é ele próprio inapreensível.
} 
jornais. Quase perdida no meio dessa profusão de hiperlinks, esconde-se uma caixa de leitura, com o título "Historia Abreviada de la Literatura Portátil (versión dissidente)". Logo abaixo, 27 itens numerados e intitulados - na verdade, 28, incluindo-se o item 27a; de "01: Valise" até "27a: La maleta de Arletty" - funcionam como hiperlinks, levando os usuários a uma página exclusiva para a "versão dissidente", onde se apresentam sequencialmente todos os itens. Nesse ambiente, a disposição dos elementos é sempre a mesma: do lado esquerdo, uma imagem; do lado direito, um número e um bloco de texto; e cada um dos itens é separado por um fio, como numa tentativa de dispor os fragmentos em ilhas isoladas.

Em termos de conteúdo, já no primeiro item fica claro que não se trata de uma continuação do livro de 1985 ou de uma releitura, mas sim de um jogo de memória, em que novamente a narrativa histórica e ficcional coadunam-se para costurar um relato. Só que, desta vez, o mote é metalinguístico: trata-se da construção da própria página sobre a "versão dissidente". Nessa comunicação epistolar de via única, o narrador deixa de ser difuso - como no livro -, tomando de forma inequívoca a voz de Vila-Matas. Essa característica evidencia-se desde o primeiro item, que apresenta a imagem de uma maleta antiga, acompanhada do seguinte texto: "Se você quiser, deixamos para a sua volta das férias a página de História abreviada, já que ainda não sei como dar um foco a ela". ${ }^{15} \mathrm{O}$ escritor exibe-se, assim, como alguém que não apenas está oscilante quanto ao ambiente, mas também como um personagem que se comunica com um interlocutor, que poderia ser um editor ou mesmo um encarregado de auxiliá-lo na tarefa de construção da página. No segundo item, ao lado de uma imagem do escritor irlandês Laurence Sterne - menção de destaque no livro -, o escritor parece compartilhar o seu processo criativo para a criação da página: "De fato, a página irá narrando a tentativa de construção dela mesma.". ${ }^{16}$ E assim se segue essa espécie de relato numerado, em que Vila-Matas divide com o leitor diferentes informações sobre as referências do livro, sempre com um tom irônico que se assemelha ao do narrador do livro. No item 06, por exemplo, ao lado de uma imagem que apenas apresenta o número 27, questiona: "Não sei, sinto que esta página ainda nem começou. Você acha que quando chegarmos à entrada $27-0$ número shandy por excelência - já teremos nascido?". 17 Trata-se, portanto, de um pacto com o usuário-leitor que mais uma vez se estabelece por meio da dúvida e da desconfiança.

\footnotetext{
${ }^{15}$ No original, "Si quieres, dejamos para tu regreso de vacaciones la página de Historia abreviada, ya que no sé todavía cómo enfocarla". Tradução minha.

${ }^{16}$ No original, "De hecho, la página irá narrando el intento de construcción de la misma.”. Tradução minha.

${ }^{17}$ No original, "No sé, siento como si esta página aún no hubiera ni empezado. ¿Crees que cuando lleguemos a la entrada 27

-número shandy por excelencia- habremos ya nacido?”. Tradução minha.
} 
Em termos de experiência, não há dados visíveis sobre a data de publicação da página, o que impacta diretamente as ferramentas de criação disponíveis. Ainda assim, nota-se que não existe um desenvolvimento de estruturas mais complexas, com o uso programático de hiperlinks, a criação multimídia e os diferentes procedimentos que têm trabalhado a partir do excesso de informação do ambiente digital, redefinido não apenas as atividades de escrita e leitura como o próprio lugar da literatura. Kenneth Goldsmith (2011, p. xviii), por exemplo, um dos escritores que desafia os limites do literário, explora a escrita da cópia e da apropriação, defendendo um uso manipulável e compartilhável da palavra. Já na página de Vila-Matas, é curioso observar que existe uma experiência de leitura quase invertida nos meios impresso e eletrônico: enquanto no livro não apenas o título, mas também o reduzido número de páginas são abreviados, no ambiente virtual, conhecido pelas formas brevíssimas, os blocos de texto dos 28 itens apresentam um volume quase incompatível com os atributos digitais de expressão. Além disso, ainda que a escrita da versão dissidente seja fragmentária, a numeração e a separação de itens também parece não se conformar ao novo meio.

De toda forma, embora a página de Vila-Matas pareça estática em relação a outras experiências literárias em meio digital, tal como se houvesse sido construída em um momento no qual as potencialidades da literatura eletrônica ainda estavam incipientes, a "versão dissidente" faz parte do universo semântico da ciberliteratura, o que traz implicações para o seu processo criativo. Piret Viires $(2005$, p. 154) configura a ciberliteratura como um termo guarda-chuva que poderia incluir todos os textos literários disponíveis na internet, a exemplo de textos em prosa e poesia nas páginas de escritores profissionais. Com isso, se o escritor catalão não desenvolveu de forma mais inventiva as possibilidades da literatura eletrônica, o que resultou numa experiência mais paratextual do que propriamente hipertextual, tateou um terreno que ainda pode render projetos futuros. Já na sua relação com a arte contemporânea, a imersão mostra-se mais interessada, na busca de um diálogo que amplie as suas ferramentas, como se analisará a seguir.

\section{Toda arte é contemporânea}

"Literatura expandida: todo el arte es contemporáneo, el de ayer y el del remoto mañana" é o sugestivo título de um artigo que Vila-Matas publicou no dia 15 de maio de 2017, na sua coluna do jornal El País, chamada Café Perec. Nesse pequeno texto, cujo mote principal é uma análise do livro Cronografías. Arte y ficciones de un tiempo sin tempo (2017), 
da argentina Graciela Speranza, o escritor catalão reflete sobre o estado da arte contemporânea, destacando movimentos de campos em expansão nas obras de literatos e artistas que trasladam dos textos à visualidade (e vice-versa). O subtítulo do artigo é repetido no corpo do texto, quando Vila-Matas desenvolve a ideia de que viria do livro a capacidade de lembrar que toda a arte, de qualquer época, é contemporânea. Para isso, evoca uma temporalidade não linear, que inclui as montagens mnemônicas de Aby Warburg. Mais do que uma crítica distanciada, esse entusiasmo demonstra uma gradual conexão do escritor com a arte contemporânea, que beira uma ideia de missão dentro da sua própria atuação, a partir de um deslizamento da literatura para a arte.

É interessante notar, em primeiro lugar, o quanto Vila-Matas carrega, com frequência, personagens de outros domínios para seus romances, com especial atenção para os artistas. Se Historia abreviada... construiu-se em grande parte devido à reunião de diferentes personagens, esse tipo de referência retorna já no título de livros como Chet Baker piensa en su arte (2011) e Aire de Dylan (2012), mas também em tramas variadas, a exemplo da falsa entrevista que "promoveu” com Marlon Brando, no livro El viajero más lento (1992). Essa curiosidade, que guarda uma espécie de voyeurismo, pouco a pouco consolida-se no próprio fazer do escritor, o qual se permite cada vez mais flertar com procedimentos das artes visuais.

No conto "Porque ela não pediu isso", publicado em Exploradores do abismo (2013), Vila-Matas constrói mais um desnorteante estratagema, inspirado por Sophie Calle. Tudo se inicia com Rita Malú, uma imitadora da artista francesa, que, cansada da própria vida, decide transformar-se em uma detetive particular, fazendo da residência um escritório e mudando o próprio sobrenome. "Podemos encontrar a pessoa mais escondida da terra", dizia o anúncio publicado pela personagem, antes de fechar o escritório por causa de uma proposta inusitada (VILA-MATAS, 2013, p. 387). Na segunda parte do conto, o escritor revela ter acordado um pacto com a própria Calle, num intercâmbio artístico segundo o qual Vila-Matas escreveria a maneira como a artista francesa viveria a sua vida durante um período de tempo. O projeto, no entanto, jamais teria ido adiante, deixando o escritor em um estado de angústia e semiparalisia:

Aquela proposta de Sophie me fez pensar que o que ela procurava era o desaparecimento do autor, justamente o que em meus últimos textos eu dizia desejar tanto, sem ousar levá-lo a cabo, limitando-me apenas a esfumar minha identidade em meus escritos. (idem, p. 420) 
Para ampliar a sensação labiríntica, o narrador, mais adiante, declara ter inventado o pacto com Calle e, finalmente, ela própria - como personagem ficcional - procura Vila-Matas, fazendo-lhe a mesma proposta que o escritor antes afirmara jamais ter existido. Observa-se, assim, a insistente reverência à figura do artista, que neste caso se apresenta a partir de relações de vizinhança, permuta e oscilações.

Vale lembrar que Calle também aproximou-se da escrita em obras como L'hotel. Ecrit sur l'image (1984) e The Address Book (2012), quando incluiu textos e imagens nas publicações que resultaram de suas performances, tal como a composição integrada de um percurso narrativo. ${ }^{18}$ Mas a questão literária toma protagonismo na relação de fertilização cruzada entre a artista francesa e o escritor Paul Auster, quando foram geradas as obras Leviatã (1992), Double Game (1999) e Gotham Handbook (2004). De Leviatã (1992), livro no qual Auster constrói a personagem Maria Turner à semelhança de Calle, descrevendo dez trabalhos performáticos da personagem ficcional, surge Double Game (1999), em que a artista francesa decide realizar as duas únicas ações da personagem que eram fictícias. Finalmente, Gotham Handbook (2004) deriva da proposta (não aceita) de Calle a Auster, solicitando ao escritor que roteirizasse suas próprias ações durante um ano, a partir da criação de um personagem ficcional. Em seu lugar, surgiram instruções para que Sophie Calle melhorasse a sua vida em Nova Iorque, que incluíam:

(...) sorrir em todas as circunstâncias, tomando o cuidado de não dirigir-se a homens e contabilizando as respostas positivas; falar com desconhecidos, tendo como pretexto comentários sobre as condições meteorológicas; oferecer sanduíches (ou vales-refeição do McDonald's) e cigarros a mendigos e sem-teto; adotar um lugar e transformá-lo numa extensão da própria personalidade. (FABRIS, 2009)

Portanto, ao convocar Calle para seu próprio universo criativo, Vila-Matas carrega tanto um repertório da arte contemporânea como a sua permuta com as formas literárias e a sua experiência com Auster, que retorna aqui como pastiche.

Essa atração pelos artistas contemporâneos confirma-se também em Marienbad Électrique (2015), quando o escritor revela, a partir de conversas, suas reflexões e inúmeras colaborações com a artista francesa Dominique González-Foerster, que antes disso já havia se tornado personagem de Vila-Matas, no livro Dublinesca (2011).

\footnotetext{
${ }^{18}$ L'hotel. Ecrit sur l'image (1984) é resultado da performance The Hotel (1981), em que Calle compartilha imagens e textos sobre hóspedes de um hotel, onde atuou como camareira de durante três semanas. Já The Address Book (2012) construiu o perfil de um estranho a partir das impressões dos contatos que estavam registrados no caderno de endereços que havia perdido.
} 
Para mim, foi importante conhecer Gonzalez-Foerster há oito anos - entre outras coisas, porque entrei em contato com uma geração de artistas franceses que recusaram recolher-se em si mesmos e situaram o trabalho deles em uma interseção de disciplinas e de intercâmbio de ideias com as demais artes. ${ }^{19}$

Se todas essas experiências retratam interesses e eventualmente parcerias que reforçam os vínculos de Vila-Matas com as artes, o escritor mantinha-se até então protegido pela distância segura de termo como "inspiração", "intercâmbio" e "trânsito". Essa mobilidade torna-se "extraordinária" apenas quando apresenta-se como uma experiência física. Como um odradek, o portátil escritor permite-se mudar de corpo, quando é convidado para participar da Documenta de Kassel (edição 13, em 2012), o maior evento mundial de arte contemporânea. Desta vez, ele não estaria como professor, palestrante ou convidado especial, mas deveria, como em uma performance, guiar-se pela seguinte instrução: durante três semanas, escreveria em um café próximo, sendo observado pelos clientes e passantes. Após uma recusa inicial, Vila-Matas convenceu-se de que a experiência valeria a viagem: "Tinha curiosidade, além do mais, de ver se havia muita diferença entre a vanguarda literária do momento - de existência duvidosa - e a vanguarda da arte, que se reunia a cada cinco anos na Documenta" (VILA-MATAS, 2015, p. 19-20). Foi assim que a sua habitual escrita como performance tornou-se a performance da escrita, e Vila-Matas transformou o fazer literário em um exemplar do gabinete contemporâneo de curiosidades. Dessa experiência resultou o livro Não há lugar para a lógica em Kassel (2015), que relata sobretudo um confronto do escritor com as instalações e obras da exposição, entre preconceitos ironicamente analisados e descobertas de um mundo em construção. Nas palavras do escritor, a experiência é um retorno aos dias em que tinha como eixo de vida tentar ser vanguardista e, mais ainda, investiga as suas relações com o vanguardismo, revigorando o seu olhar sobre a arte contemporânea: “(...) o mais provável era que eu tivesse um preconceito velho e tosco contra a arte contemporânea e fosse um dos que acreditavam que, nos dias atuais, a arte era um verdadeiro desastre ou uma grande piada, ou qualquer coisa do tipo.” (idem, p. 16-7).

\footnotetext{
${ }^{19}$ No original, "Para mí fue importante hace ocho años conocer a Gonzalez-Foerster, entre otras cosas porque entré en contacto con una generación de artistas franceses que se negaron a replegarse en sí mismos y situaron su trabajo en una intersección de disciplinas y de intercambio de ideas con las demás artes”. Tradução minha. Ver a autobiografia comentada

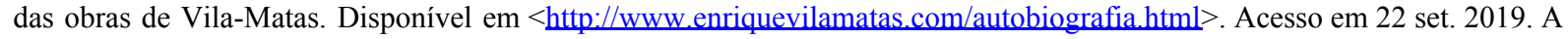
pesquisadora Ana Pato explora as obras de Vila-Matas e da artista francesa no seu livro Literatura expandida: arquivo e citação na obra de Dominique Gonzalez-Foerster (2012). Segundo Pato (2012, p. 39-40), a obra da artista francesa procura uma ligação com a literatura que "transcende a esfera do objeto", expandindo a criação literária para o espaço expositivo.
} 
Nasce assim um Vila-Matas diferente, que assume o corpo de um autor conceitual, como reconheceu em entrevista ao jornal $A B C$. "Na verdade, foi quando me convidaram para ir a Kassel que me dei conta de que eu poderia fazer o que quisesse com o que via". (VILA-MATAS, 2016). Se, de alguma maneira, atender pela categoria de "autor conceitual" liberta a sua prática de procedimentos mais normativos, também assume o risco de construir uma filiação. Portanto, Vila-Matas passa das vanguardas como tema para a arte conceitual como experiência.

No clássico artigo “A desmaterialização da arte” (1968), Lucy R. Lippard e John Chandler consolidam um exercício analítico sobre essa arte ainda em estado de pleno desenvolvimento. Para os críticos, embora o termo "arte conceitual" abarcasse trabalhos de vertentes heterogêneas, eles se assemelhavam por enfatizar o pensamento e por estabelecer novas relações no processo artístico, transformando o ateliê não mais em um local de execução das obras, mas sim em um espaço de estudo. Os críticos desenhavam ainda diferentes tendências que não apenas orientavam a nova arte, mas que também representavam diferentes pontos de partida:

As artes visuais, no momento, parecem pairar numa encruzilhada que bem se poderia revelar como duas estradas para um mesmo lugar, apesar de aparentarem vir de duas fontes: arte como ideia e arte como ação. No primeiro caso, a matéria é negada, pois a sensação foi convertida em conceito; no segundo caso, a matéria foi transformada em energia e tempo-movimento. (LIPPARD; CHANDLER, 2013, p. 152)

Se a arte conceitual colaborou para derrubar os dogmáticos pedestais que separavam diferentes tipos de expressão, também a literatura (ou uma certa literatura) procurou realocar-se diante da arte como ideia e da arte como ação. Foi o estudo da linguagem especialmente nos anos 1970 - que permitiu a grupos como o Fluxus e a arte pop que abrissem as portas para a materialidade da palavra nos espaços das artes visuais, a partir de uma reconfiguração da poesia, em consonância com a arte de performance e a música experimental de matriz cageana (KOTZ, 2007, p. 1). Em Words to be looked at - Language in 1960s Art (2007), Liz Kotz identifica que naquele momento emergiram dois tipos de prática na poesia. O primeiro deles, relacionado especialmente a Fluxus e os "event cards" de George Brecht, consistia de instruções curtas que propunham ações, experiências e processos. O

\footnotetext{
${ }^{20}$ No original, "Sí, en realidad cuando me invitaron a Kassel fue cuando yo me di cuenta de que podía hacer lo que quisiera con lo que veia". Tradução minha.
} 
segundo, encontrado em trabalhos tão diferentes quanto o livro 5 biblical poems (1954-55), de Jackson Mac Low, e o poema "Europe" (1962), de John Ashbery, usava justaposições e sobreposições de materiais pré-existentes, ativando empréstimos de textos variados (KOTZ, 2007, p. 100-117). Foi assim que variados artistas, como Joseph Kosuth, Sol LeWitt, Dan Graham, Carl Andre, Vito Acconci, Cildo Meireles, Lawrence Weiner, Richard Serra, tomaram a palavra como matéria para os seus trabalhos daquele momento.

A obra de Vila-Matas parece trilhar uma encruzilhada análoga, oscilando entre a literatura como ideia e a literatura como ação, especialmente a partir de Kassel. Trata-se, mais ainda, de um terreno movediço, compartilhado com outros pares, como Mario Bellatín e Gonçalo M. Tavares, ${ }^{21}$ que implica uma liberdade de ferramentas sem a segurança dos limites disciplinares. Como analisa Paula Juanpere (2018, p. 109), “A literatura expandida é, para Vila-Matas, aquela prática artística, literária ou visual, que busca no outro campo - no outro idioma - uma possibilidade de expansão, de experimentação, de ampliação de limites imaginários e formais". 22 Os domínios, nesse sentido, são campos abertos para que diferentes linguagens fluam ao gosto de cada projeto.

Portanto, inserir a sua obra na esfera do conceitualismo significa reconhecer uma sintaxe conceitual em seus trabalhos que amplia o terreno do escritor, ao mesmo tempo em que reorienta percursos de leitura. Mas também manifesta a necessidade de se administrar uma outra teia intertextual na sua criação artística, tornando-se via de acesso à própria arte conceitual. Se, como comprovou Joseph Kosuth (1999, p. 164), “Toda arte (depois de Duchamp) é conceitual (por natureza) porque a arte existe apenas conceitualmente", não é casual a aferrada admiração de Vila-Matas pelo artista francês, ao ponto de o narrador de Historia abreviada... questionar: "Será Duchamp meu odradek?”23 (VILA-MATAS, 1985, p. 64). Duchamp carrega consigo não apenas a transformação de todas as artes a partir da sua crítica bem humorada às formas estéticas, mas também as suas malas e a sua capacidade de ser portátil.

\footnotetext{
${ }^{21}$ No artigo "Uma exposição de arte visível em Gonçalo M. Tavares" (2019), Reginaldo Pujol Filho também procura alocar Gonçalo M. Tavares no âmbito da arte contemporânea. No artigo, o autor descreveu cenas dos livros Matteo perdeu o emprego, O senhor Calvino, O senhor Juarroz e Uma menina está perdida no seu século à procura do pai, que se assemelhavam a obras de uma exposição. O que Pujol Filho propõe é que o olhar sobre determinadas cenas, páginas e capítulos do escritor poderia ser complementado sob a perspectiva de que atuam como trabalhos de arte conceitual.

${ }^{22}$ No original, "La literatura expandida es, para Vila-Matas, aquella práctica artística, literaria o del ámbito visual, que busca en el otro terreno - en el otro lenguaje - una posibilidad de expansión, de experimentación, de ampliación de imaginario y límites formales". Tradução minha.

${ }^{23}$ No original, “¿Será Duchamp mi odradek?”. Tradução minha.
} 


\section{REFERÊNCIAS}

BENJAMIN, Walter. Escritos sobre mito e linguagem (1915-1921). São Paulo: Editora 34, 2011.

. The Arcades Project. Cambridge, MA: Harvard University Press, 1999.

CAMPBELL, Brenna; LÉVÈQUE, Élodie; JUE, Erin. Marcel Duchamp's Boîtes-en-valise:

Collaboration and conservation. Studies in Conservation, 57: sup1, S52-S60, 2012.

CHANDLER, John; LIPPARD, Lucy. A desmaterialização da arte. Arte \& ensaios

(PPGAV/EBA/UFRJ), Rio de Janeiro, n. 25, p. 150-165, maio 2013.

DEMOS, T.J. Duchamp's Boîte-en-valise: Between Institutional Acculturation and

Geopolitical Displacement. Grey Room 08, Summer 2002, p. 6-37.

IZABEL, Tomaz Amorim. Odradek, quimera incapturável. Pandaemonium ger., São Paulo, v. 19, n. 28, p. 74-100, out. 2016. Disponível em

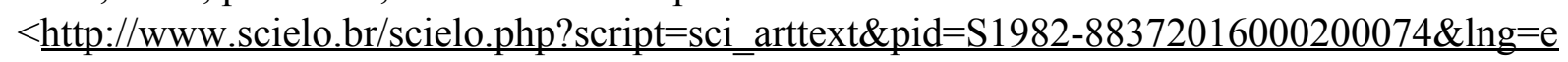

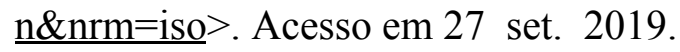

KAFKA, F. A tribulação de um pai de família. In: SCHWARTZ, R. O pai de família. São Paulo: Companhia das Letras, 2008, p. 22-28.

KOSUTH, Joseph. Art After Philosophy. In: ALBERRO, Alexander; STIMSON, Blake (eds.). Conceptual Art: A Critical Anthology. Cambridge: MIT Press, 1999, p. 158-177. KOTZ, Liz. Words to be looked at: language in 1960s art. Cambridge, Mass.: MIT Press, 2010.

FABRIS, Annateresa. Sophie Calle: entre imagens e palavras. ARS (São Paulo), São Paulo, v. 7, n. 14, p. 68-85, 2009. Disponível em

$<\underline{\text { http://www.scielo.br/scielo.php?script }=\text { sci arttext\&pid }=\text { S167853202009000200006\&lng }=\text { en }}$ $\underline{\text { \&nrm }=\text { iso }}>$. Acesso em 22 set. 2019.

GOLDSMITH, Kenneth. Why Conceptual Writing? Why Now? In: DWORKIN, Craig, GOLDSMITH, Kenneth (eds.). Against expression: an anthology of conceptual writing.

Evanston, IL: Northwestern UP, 2011, p. xvii-xxii.

JUANPERE, Paula. Del arte expandido a la literatura expandida: Una aproximación a la posibilidad de la expansión de lo literario en las artes visuales contemporáneas. $452{ }^{\circ} \mathrm{F}$, n. 19 , p. 102-113, 2018.

PATO, Ana. Literatura expandida: arquivo e citação na obra de Dominique

Gonzalez-Foerster. São Paulo: Sesc / Videobrasil, 2012.

PIRES, Paulo Roberto. Resenha de "História abreviada da literatura portátil", de Vila-Matas.

O Globo, 02/04/2011. Disponível em

$<\underline{\text { https://blogs.oglobo.globo.com/prosa/post/resenha-de-historia-abreviada-da-literatura-portati }}$ 1-de-vila-matas-372458.html >. Acesso em 22 set. 2019.

PUJOL FILHO, Reginaldo. Uma exposição de arte visível em Gonçalo M. Tavares. Revista de Estudos Literários, [S.1.], v. 8, p. 251-273, jan. 2019. ISSN 2183-847X. Disponível em $<$ https://impactum-journals.uc.pt/rel/article/view/6177>. Acesso em 23 set. 2019.

SCHWARZ, Roberto. O pai de família e outros estudos. São Paulo: Companhia das Letras, 2008.

VIIRES, Piret. Literature in Cyberspace. Folklore: Electronic Journal of Folklore, 29, p. 153-174, 2005.

VILA-MATAS, Enrique. Enrique Vila-Matas: Un día en la calle me preguntaron: ¿Pero cómo es que te gusta el arte contemporáneo? (entrevista a Laura Revuelta). $A B C, 29 / 02 / 2016$.

Disponível em 
$<$ abc.es/cultura/cultural/abci-calle-preguntaron-pero-como-gusta-arte-contemporaneo-201602 242037 noticia.html>. Acesso em 22 set. 2019.

. Literatura expandida: todo el arte es contemporáneo, el de ayer y el del remoto mañana. El País (coluna Café Perec), 15/05/2017. Disponível em $<$ https://elpais.com/cultura/2017/05/15/actualidad/1494857844_582692.html $>$. Acesso em 22 set. 2019.

. Exploradores do abismo (e-book). São Paulo: Cosac \& Naify, 2013.

. Historia abreviada de la literatura portátil. Barcelona: Anagrama, 1985.

. Não há lugar para a lógica em Kassel (e-book). São Paulo: Cosac \& Naify, 2015. 